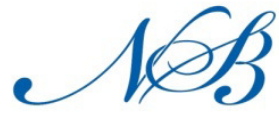

Notulae Scientia Biologicae

Original Article

\title{
Application of Chondroitin Sulfate on Organogenesis of Two Cymbidium spp. under Different Sources of Lights
}

\author{
Syeda J. NAHAR ${ }^{1 *}$, Syed M. HAQUE ${ }^{1}$, Shimasaki KAZUHIKO² \\ ${ }^{1}$ Ehime University, The United Graduate School of Agricultural Sciences, 3-5-7 Tarumi, Matsuyama, Ehime 790-8556, \\ Japan;naharmunna@yahoo.com (*correspondingauthor); guddu7771@gmail.com \\ ${ }^{2}$ Kochi University, Faculty of Agriculture, B200Monobe, Nankoku, Kochi 783-8502,Japan; shim@kochi-u.ac.jp
}

\begin{abstract}
The aim of this study was to present chondroitin sulfate as a plant growth regulator and to give an overview about light effects on PLBs (protocorm like bodies) culture of Cymbidium dayanum and Cymbidium finlaysonianum cultured in vitro. Chondroitin sulfate is a sulfated glycosaminoglycan (GAG) composed of a chain of alternating sugars $\mathrm{N}$-acetylgalactosamine and glucuronic acid. It is widely used as a material for food ingredients, cosmetics and medicine. PLBs were cultured on modified MS medium containing different concentration of chondroitin sulfate $(0,0.1,1$ and $10 \mathrm{mg} / \mathrm{l})$, under four sources of lights: conventional white fluorescent tube, red LED, green LED and blue LED. In $C$. dayanum, 100\% PLBs formation rate was observed at $0.1 \mathrm{mg} / \mathrm{l}$ chondroitin sulfate with modified MS medium under green LED and $1 \mathrm{mg} / \mathrm{l}$ chondroitin sulfate under blue LED; the maximum shoots and roots formation were observed under green LEDs ( $93 \%$ and $80 \%$ respectively) when media contained $0.1 \mathrm{mg} / \mathrm{l}$ chondroitin sulfate. In C. finlaysonianum, every concentrations of chondroitin sulfate enhanced the growth rate of PLBs when compared to control treatment, under all four sources of lights. The highest values were recorded with $0.1 \mathrm{mg} / \mathrm{l}$ chondroitin sulfate which induced $100 \% \mathrm{PLBs}$ formation under blue LED, while 10 $\mathrm{mg} / \mathrm{l}$ chondroitin sulfate had induced $100 \%$ PLBs formation under green LED. The highest percentage of shoots $(73 \%)$ was initiated in the medium containing $10 \mathrm{mg} / \mathrm{l}$ chondroitin sulfate under green LED. Plant development was strongly influenced by the light quality and plant growth regulator functions as chemical messengers for intercellular communication of plant. The results demonstrated that low concentrations of chondroitin sulfate could promote PLBs, shoots and roots formation of Cymbidium spp. under green and blue LED.
\end{abstract}

Keywords: elicitor, LED, light effect, plant growth regulator, organogenesis

\section{Introduction}

Cymbidium is a historically important orchid since it was the first ever orchid to be propagated in vitro, although those studies used shoot tip culture, and not PLBs (Morel, 1960). In Cymbidium, the PLB developmental programme is influenced by several factors such as the choice of plant growth regulators (PGR), culture conditions or explants used with PLBs forming new PLBs (Teixeira da Silva and Tanaka, 2006). Plant cell and tissue culture strategies are an attractive alternative to the use of whole plants for the production of high-value secondary metabolites and has been the subject of extended research in the last decades.

In tissue culture, the concentration of growth regulators in the medium must be optimized and may change according to the desired result.

Plant growth regulators function as chemical messengers for intercellular communication of plant. In the current study, the chondroitin sulfate was highlighted as plant growth regulator (Nahar, 2013) in order to stimulate PLBs culture of Cymbidium dayanum and C. finlaysonianum under different sources of lights. Chondroitin sulfate chains are unbranched polysaccharides of variable length, containing two alternating monosaccharides: D-glucuronic acid (GlcA) and N-acetyl-D-galactosamine (GalNAc). It is a major component of extracellular matrix, and is important in maintaining the structural integrity of tissues. Clinical studies have not identified any significant side effects or overdoses of chondroitin sulfate, which suggests its longterm safety (Hathcock and Shao, 2007). Chondroitin sulfate readily interacts with proteins in the extracellular matrix due to its negative charges. These interactions are important for regulating a diverse array to cellular activities. The efficiency of the elicitation process depends on the plant material, contact time and elicitor concentration. The simultaneous use of elicitation by chondroitin sulfate and different sources of light irradiation in Cymbidium insigne PLBs cultures resulted in a significant synergistic enhancement of PLBs, shoots and roots accumulation, showing the potential of integrated processes on chondroitin sulfate accumulation under in vitro conditions (Nahar et al., 2012). 
Light is a requirement for plant growth and development that interacts powerfully with other variables to define plant responses to the environment. New light sources for horticultural applications, intended to replace HPS lamps or fluorescent tubes, are currently being devoted to LEDs (light-emitting diodes) technology. LEDs have numerous technical advantages for plant lighting, including cool emitters that allow close placement to plant surfaces without scorching them (Mitchell, 2012). Thus, plant researchers have experimented with solid-state lightemitting diodes (LEDs). LEDs are expected to reduce the electricity costs of lighting and cooling because they have a higher efficiency of converting electric power to light power and exert lower cooling loads than conventional light sources (Goto, 2012).

Therefore, the present study was undertaken to investigate the effects of different concentrations of chondroitin sulfate, to standardize a suitable light for plantlet regeneration, shoots and roots multiplication from PLBs and find out the best light source for PLBs culture of C. dayanum and C. finlaysonianum.

\section{Materials and Methods}

\section{Plant materials}

Protocorm-like bodies (PLBs) of Cymbidium spp. were collected from local orchid growers. PLBs of Cymbidium spp. were proliferated in the modified MS medium (Shimasaki and Uemoto, 1990) by transferring to a new medium every two months. After excision of PLBs (appox. $5 \mathrm{~mm}$ in diameter) into pieces, they were used for explants.

\section{Culture conditions}

MS medium with $412.5 \mathrm{mg} / \mathrm{lammonium}$ nitrate, 950 $\mathrm{mg} / \mathrm{l}$ potassium nitrate, $20 \mathrm{~g} / \mathrm{l}$ sucrose and $2 \mathrm{~g} / \mathrm{l}$ Phytagel (Sigma) were used. After preparing the media, $\mathrm{pH}$ was adjusted to 5.5-5.8 using $0.1 \mathrm{mM}$ 2-(N-morpholino) ethanesulfonic acid sodium salt (MES-Na) before autoclaved at $121{ }^{\circ} \mathrm{C}$ for 15 minutes. Plant growth regulators (PGRs) like chondroitin sulfate (Coach Industries Inc., Japan) were added to culture media at different concentrations (control, $0.1,1$ and $10 \mathrm{mg} / \mathrm{l}$ ) before sterilization, to ascertain the growth response of the culture. PGRs-free medium were used as control. Jars of $250 \mathrm{ml}$ (UM culture bottle, As one, Japan) with plastic caps were used; each recipient receiving $30 \mathrm{ml}$ of medium.

Five in vitro PLBs were placed in each culture vessel and three culture vessels were used for each treatment. The experiment was set up in completely randomized design and conducted at the Laboratory of Vegetable and Floricultural Sciences, Faculty of Agriculture, Kochi University, Japan.

\section{Light treatments}

Generally, white fluorescent tubes were used for in vitro cultures. In the present study the investigation of the effects of chondroitin sulfate as a plant growth regulator under LED lights was tested, including conventional fluorescent tube.

The cultures of in vitro plantlets were illuminated using different light conditions of photon flux density (PFD) of $50 \mu$ mole $\mathrm{m}^{-2} \mathrm{~s}^{-1}$. There were used four sources of light: white fluorescent tube (National FL20SS), red LED (Jefcom, P18W-E1701-R, peak wavelength: $640 \mathrm{~nm}$ ), blue LED (Jefcom, P18W-E1701-B, peak wavelength: $450 \mathrm{~nm}$ ) and green LED (Jefcom, P18W-E1701-G, peak wavelength: $510 \mathrm{~nm}$ ).

All cultures were maintained at $25 \pm 1{ }^{\circ} \mathrm{C}$ under different sources of lights during 16 hour photoperiod for 5 to 7 weeks.

\section{Data analysis}

Experimental data were collected after 5 to 7 weeks of culture by counting the number of PLBs, shoots and roots; percentage of PLBs, shoots and roots were measured. The data were analyzed as one-way analysis variance (ANOVA) and differences between means were tested using Tukey's honestly significant different test $(\mathrm{P} \leq 0.05)$.

\section{Results and Discussion}

In vitro regeneration of plantlets offers a feasible propagation method in orchids and can be utilized for the year round and rapid propagation of orchid plants. Light is a fundamental environmental cue in the life of plants, playing crucial roles, directly and indirectly, in the regulation of plant development and growth (Molini and Muleo, 2003), whereas plant growth regulators are generally used to efficiently proliferate PLBs, shoot and root formation in orchid plants cultured in vitro (Chugh et al., 2009).

In vitro growth of PLBs in modified MS medium supplemented with chondroitin sulphate, under different sources of lights

Different concentrations of chondroitin sulfate on in vitro growth of PLBs of Cymbidium spp. under different light sources have been presented in Tables 1 and 2. The results revealed that chondroitin sulfate had significant influence on the different parameters studied for Cymbidium spp.

In C. dayanum, 100\% PLBs formation rate was observed at $0.1 \mathrm{mg} / \mathrm{l}$ chondroitin sulfate (with modified MS medium) under green LED and $1 \mathrm{mg} / \mathrm{l}$ chondroitin sulfate under blue LED. The concentration of $10 \mathrm{mg} / \mathrm{l}$ chondroitin sulfate induced maximum formation of PLBs $(67 \%)$ under white fluorescent tube, while under red LED $1 \mathrm{mg} / \mathrm{l}$ and 10 $\mathrm{mg} / \mathrm{l}$ chondroitin sulfate induced maximum formation of PLBs (67\%) after 5 weeks of culture periods. Comparatively, the lowest formation rate of PLBs (33\%) was observed at control (PGRs free), under green LED among four sources of lights. The highest average number of PLBs (7.8 PLBs/explant) was recorded on medium containing $0.1 \mathrm{mg} / \mathrm{l}$ chondroitin sulfate under green LED, whereas the lowest number of PLBs was found under white fluorescent tube.

In C. finlaysonianum, every concentrations of chondroitin sulfate enhanced the growth rate of PLBs when compared to control treatment. The concentration of 0.1 $\mathrm{mg} / \mathrm{l}$ chondroitin sulfate had induced 100\% PLBs formation under blue LED, whereas $10 \mathrm{mg} / \mathrm{l}$ chondroitin sulfate had induced $100 \%$ PLBs formation under green LED. The treatment with $1 \mathrm{mg} / \mathrm{l}$ chondroitin sulfate induced the maximum formation rate of PLBs (70\%) under 
158

white fluorescent tube; $0.1 \mathrm{mg} / \mathrm{l}$ and $1 \mathrm{mg} / \mathrm{l}$ chondroitin sulfate induced maximum formation rate of PLBs (87\%) under red LED. Among the four sources of lights tested, the lowest formation rate of PLBs (40\%) was observed at control (PGRs free) under white fluorescent tube after 7 weeks of culture periods. The maximum number of PLBs (18.7 PLBs/explant) was observed at $0.1 \mathrm{mg} / \mathrm{l}$ chondroitin sulfate under red LED, while the minimum number of PLBs (1.7 PLBs/explant) was observed under white fluorescent tube at control.

These results were supported with previous data on $C$. insigne (Nahar et al., 2012), whereas it was observed that chondroitin sulphate, at every concentration tested, enhanced the growth of PLBs and shoots formation when compared to control treatment; even green LED showed best formation of PLBs and shoots. Xu et al. (2009) reported that PLBs cultured under red LEDs showed the lowest differentiation rate, compared to blue LEDs, which resulted in the highest differentiation rate in cultures of Oncidium cultured in vitro. Blue LEDs might play an important role in stimulating PLB formation from callus as PLBs formed very well in blue LED treatments of Cymbidium orchid (Van et al., 2004). The hereby study results partially supported with those of Van et al. (2004) noted for $C$. dayanum, when the maximum formation of PLBs was found under blue LED.

In vitro growth of shoots and roots in modified $M S$ medium supplemented with chondroitin sulphate, under different sources of lights

Results showed that adventitious shoot and roots formation were the highest in $C$. dayanum PLBs cultured under green LEDs ( $93 \%$ and $80 \%$ respectively) when media contained $0.1 \mathrm{mg} / \mathrm{l}$ chondroitin sulfate (Table 3 and Table 5), after 5 weeks of culture. Furthermore, 0.1 $\mathrm{mg} / \mathrm{l}$ chondroitin sulfate produced a significantly higher number of shoots (1.6 shoots/explant) and roots (1.2 roots/explant) in PLBs irradiated by green LED. Under blue LED, the maximum shoots $(60 \%)$ and roots (33\%) initiation occurred at $1 \mathrm{mg} / \mathrm{l}$ chondroitin sulfate and under red LED. $1 \mathrm{mg} / \mathrm{l}$ or $10 \mathrm{mg} / \mathrm{l}$ chondroitin sulfate increased maximum shoots formation (40\%), whereas under white fluorescent tube $10 \mathrm{mg} / \mathrm{l}$ chondroitin sulfate had induced maximum shoots and roots (33\%) formation.

Shoot initiation and number of shoots of $C$. finlaysonianum PLBs cultured to different sources of lights are presented in Table 4. There were no significance differences observed in the number of shoot initiation from PLBs under the four sources of lights. The higher percentage of shoots (73\%) was initiated in the medium containing $10 \mathrm{mg} / \mathrm{l}$ chondroitin sulfate under green LED. Under blue LED and red LED, the maximum shoot ( $40 \%$ and $53 \%$ respectively) formation was observed at $1 \mathrm{mg} / \mathrm{l}$ chondroitin sulfate treatment. Comparatively, the lowest formation of shoots was observed at control (among four sources of lights). The maximum numbers of shoots (1.3 shoots/explants) was observed under red LED and green LED, with $1 \mathrm{mg} / \mathrm{l}$ chondroitin sulfate treatment. The data were collected when root formation started (data of root formation of $C$. finlaysonianum were not shown).

Plant development is strongly influenced by the light quality, which refers to the color or wavelength reaching the plant's surface (Johkan et al., 2010). The advantages that LEDs have over fluorescent lights are their wavelength specificity, light intensity adjustability, low thermal energy output and long lifespan (Hoenecke et al., 1992; Okamoto et al., 1997). Numerous studies showed significant improvements in plant growth and morphogenesis when exposed to light emitted by LEDs.

Shoot generation and rooting are important in the realization of the potential of the cell and tissue culture techniques for plant improvement (Purnhauser et al., 1987). Chondroitin sulfate and LED lights play an important role in shoot formation and efficient root formation on Cymbidium PLBs culture. The types and concentrations of PGRs play an important role in in vitro propagation of many orchid species (Arditti and Ernst, 1993). Recently, various tissue culture techniques are used to enhance yield of secondary metabolites by trigger stress response like using elicitors.

In the current study, differences in the induction rate for PLBs were observed among the treatments with

Table 1. In vitro growth of $C$. dayanum PLBs into different concentrations of chondroitin sulfate with modified MS medium, under four sources of lights

\begin{tabular}{|c|c|c|c|c|c|c|c|c|}
\hline \multirow[b]{2}{*}{$\begin{array}{l}\text { Chondroitin } \\
\text { sulfate (mg/l) }\end{array}$} & \multicolumn{2}{|c|}{ White fluo. Tube } & \multicolumn{2}{|c|}{ Red LED } & \multicolumn{2}{|c|}{ Green LED } & \multicolumn{2}{|c|}{ Blue LED } \\
\hline & $\begin{array}{c}\text { PLBs } \\
\text { No./explant }\end{array}$ & Rate (\%) & $\begin{array}{c}\text { PLBs } \\
\text { No./explant }\end{array}$ & $\begin{array}{l}\text { Rate } \\
(\%)\end{array}$ & $\begin{array}{c}\text { PLBs } \\
\text { No./explant }\end{array}$ & $\begin{array}{l}\text { Rate } \\
(\%)\end{array}$ & $\begin{array}{c}\text { PLBs } \\
\text { No./explant }\end{array}$ & Rate (\%) \\
\hline Control & $1.4 \pm 0.5 \mathrm{a}$ & 60 & $2.1 \pm 0.8 \mathrm{a}$ & 53 & $1.1 \pm 0.8 \mathrm{c}$ & 33 & $2.7 \pm 1.0 \mathrm{~b}$ & 60 \\
\hline 0.1 & $1.0 \pm 0.5 \mathrm{a}$ & 53 & $2.5 \pm 1.1 \mathrm{a}$ & 47 & $7.8 \pm 0.9 a$ & 100 & $2.1 \pm 0.4 b$ & 93 \\
\hline 1 & $1.1 \pm 0.7 \mathrm{a}$ & 40 & $3.0 \pm 0.9 \mathrm{a}$ & 67 & $3.1 \pm 1.0 \mathrm{c}$ & 73 & $6.0 \pm 1.0 \mathrm{a}$ & 100 \\
\hline 10 & $2.2 \pm 0.8 \mathrm{a}$ & 67 & $4.5 \pm 1.4 \mathrm{a}$ & 67 & $5.2 \pm 1.3 \mathrm{abc}$ & 80 & $3.9 \pm 1.1 \mathrm{ab}$ & 73 \\
\hline
\end{tabular}

${ }^{*}$ Value represents means \pm SE followed by the different letters show significant differences by Tukey's HSD test $(\mathrm{P} \leq 0.05)$. White fluo. tube $=$ White fluorescent tube

Table 2. In vitro growth of $C$. finlaysonianum PLBs into different concentrations of chondroitin sulfate with modified MS medium, under four sources of lights

\begin{tabular}{|c|c|c|c|c|c|c|c|c|}
\hline \multirow[b]{2}{*}{ Chondroitin sulfate $(\mathrm{mg} / \mathrm{l})$} & \multicolumn{2}{|c|}{ White fluo. tube } & \multicolumn{2}{|c|}{ Red LED } & \multicolumn{2}{|c|}{ Green LED } & \multicolumn{2}{|c|}{ Blue LED } \\
\hline & $\begin{array}{c}\text { PLBs } \\
\text { No./explant }\end{array}$ & Rate (\%) & $\begin{array}{c}\text { PLBs } \\
\text { No./explant }\end{array}$ & Rate (\%) & $\begin{array}{c}\text { PLBs } \\
\text { No./explant }\end{array}$ & Rate (\%) & $\begin{array}{c}\text { PLBs } \\
\text { No./explant }\end{array}$ & Rate (\%) \\
\hline Control & $1.7 \pm 1.2 \mathrm{a}$ & 40 & $9.7 \pm 3.8$ & 60 & $8.2 \pm 1.7 \mathrm{~b}$ & 73 & $11.0 \pm 2.5 \mathrm{ab}$ & 73 \\
\hline 0.1 & $6.1 \pm 3.2 \mathrm{a}$ & 60 & $18.7 \pm 4.9$ & 87 & $10.4 \pm 1.7 \mathrm{ab}$ & 93 & $14.2 \pm 1.5 \mathrm{a}$ & 100 \\
\hline 1 & $9.3 \pm 3.6 \mathrm{a}$ & 70 & $12.6 \pm 3.8$ & 87 & $15.8 \pm 2.8 \mathrm{a}$ & 87 & $5.7 \pm 1.6 b$ & 80 \\
\hline 10 & $4.4 \pm 2.4 \mathrm{a}$ & 50 & $10.7 \pm 3.8$ & 67 & $11.1 \pm 2.1 \mathrm{ab}$ & 100 & $9.1 \pm 1.5 \mathrm{ab}$ & 93 \\
\hline
\end{tabular}


Table 3. In vitro growth of $C$. dayanum shoots into different concentrations of chondroitin sulfate with modified MS medium, under four sources of lights

\begin{tabular}{|c|c|c|c|c|c|c|c|c|}
\hline \multirow{2}{*}{$\begin{array}{l}\text { Chondroitin sulfate } \\
(\mathrm{mg} / \mathrm{l})\end{array}$} & \multicolumn{2}{|c|}{ White fluo. Tube } & \multicolumn{2}{|c|}{ Red LED } & \multicolumn{2}{|c|}{ Green LED } & \multicolumn{2}{|c|}{ Blue LED } \\
\hline & $\begin{array}{c}\text { Shoot } \\
\text { No./explant }\end{array}$ & Rate (\%) & $\begin{array}{c}\text { Shoot } \\
\text { No./explant }\end{array}$ & $\begin{array}{l}\text { Rate } \\
(\%)\end{array}$ & $\begin{array}{c}\text { Shoot } \\
\text { No./explant }\end{array}$ & $\begin{array}{l}\text { Rate } \\
(\%)\end{array}$ & $\begin{array}{c}\text { Shoot } \\
\text { No./explant }\end{array}$ & $\begin{array}{l}\text { Rate } \\
(\%)\end{array}$ \\
\hline Control & $0.3 \pm 0.2 \mathrm{a}$ & 27 & $0.5 \pm 0.2 \mathrm{a}$ & 47 & $0.4 \pm 0.2 b$ & 40 & $0.2 \pm 0.2 b$ & 20 \\
\hline 0.1 & $0.3 \pm 0.3 \mathrm{a}$ & 27 & $0.4 \pm 0.3 \mathrm{a}$ & 33 & $1.6 \pm 0.3 \mathrm{a}$ & 93 & $0.2 \pm 0.2 b$ & 20 \\
\hline 1 & $0.2 \pm 0.2 \mathrm{a}$ & 20 & $0.4 \pm 0.2 \mathrm{a}$ & 40 & $0.7 \pm 0.2 \mathrm{ab}$ & 67 & $0.8 \pm 0.3 \mathrm{a}$ & 60 \\
\hline 10 & $0.8 \pm 0.6 a$ & 33 & $0.4 \pm 0.2 \mathrm{a}$ & 40 & $0.6 \pm 0.6 b$ & 33 & $0.5 \pm 0.2 \mathrm{ab}$ & 47 \\
\hline
\end{tabular}

Table 4. In vitro growth of $C$. finlaysonianum shoots into different concentrations of chondroitin sulfate with modified MS medium, under four sources of lights

\begin{tabular}{|c|c|c|c|c|c|c|c|c|}
\hline \multirow[b]{2}{*}{$\begin{array}{l}\text { Chondroitin sulfate } \\
(\mathrm{mg} / \mathrm{l})\end{array}$} & \multicolumn{2}{|c|}{ White fluo. tube } & \multicolumn{2}{|c|}{ Red LED } & \multicolumn{2}{|c|}{ Green LED } & \multicolumn{2}{|c|}{ Blue LED } \\
\hline & $\begin{array}{c}\text { Shoots } \\
\text { No./explant }\end{array}$ & Rate (\%) & $\begin{array}{c}\text { Shoots } \\
\text { No./explant }\end{array}$ & $\begin{array}{l}\text { Rate } \\
(\%)\end{array}$ & $\begin{array}{c}\text { Shoots } \\
\text { No./explant }\end{array}$ & $\begin{array}{l}\text { Rate } \\
(\%)\end{array}$ & $\begin{array}{c}\text { Shoots } \\
\text { No./explant }\end{array}$ & $\begin{array}{l}\text { Rate } \\
(\%)\end{array}$ \\
\hline Control & 0 & 0 & 0 & 0 & $0.5 \pm 0.7 \mathrm{a}$ & 20 & $0.5 \pm 0.6 \mathrm{a}$ & 20 \\
\hline 0.1 & 0 & 0 & $0.7 \pm 0.5 a$ & 33 & $0.5 \pm 0.3 a$ & 40 & $0.3 \pm 0.2 \mathrm{a}$ & 27 \\
\hline 1 & $0.6 \pm 0.4 a$ & 40 & $1.3 \pm 0.6 \mathrm{a}$ & 53 & $1.3 \pm 0.3 \mathrm{a}$ & 20 & $0.8 \pm 0.5 \mathrm{a}$ & 40 \\
\hline 10 & $0.8 \pm 0.8 \mathrm{a}$ & 30 & $1.1 \pm 0.6 \mathrm{a}$ & 47 & $0.8 \pm 0.2 \mathrm{a}$ & 73 & $0.4 \pm 0.4 \mathrm{a}$ & 27 \\
\hline
\end{tabular}

${ }^{*}$ Values represent means \pm SE followed by the different letters show significant differences by Tukey's HSD test $(\mathrm{P} \leq 0.05)$. White fluo. tube $=$ White fluorescent tube

Table 5. In vitro growth of $C$. dayanum roots into different concentrations of chondroitin sulfate with modified MS medium, under four sources of lights

\begin{tabular}{lcccccccc}
\hline \multirow{2}{*}{$\begin{array}{l}\text { Chondroitin sulfate } \\
(\mathrm{mg} / \mathrm{l})\end{array}$} & \multicolumn{2}{c}{ White fluo. tube } & \multicolumn{2}{c}{ Red LED } & \multicolumn{2}{c}{ Green LED } \\
\cline { 2 - 7 } & $\begin{array}{c}\text { Root } \\
\text { No./explant }\end{array}$ & $\begin{array}{c}\text { Rate } \\
(\%)\end{array}$ & $\begin{array}{c}\text { Root } \\
\text { No./explant }\end{array}$ & $\begin{array}{c}\text { Rate } \\
(\%)\end{array}$ & $\begin{array}{c}\text { Root } \\
\text { No./explant }\end{array}$ & $\begin{array}{c}\text { Rate } \\
(\%)\end{array}$ & $\begin{array}{c}\text { Root } \\
\text { No./explant } \\
(\%)\end{array}$ \\
\hline Control & $0.3 \pm 0.3 \mathrm{a}$ & 20 & $0.2 \pm 0.2 \mathrm{a}$ & 20 & $0.3 \pm 0.2 \mathrm{~b}$ & 40 & $0.2 \pm 0.2 \mathrm{a}$ & 20 \\
0.1 & $0.5 \pm 0.5 \mathrm{a}$ & 27 & $0.3 \pm 0.3 \mathrm{a}$ & 20 & $1.2 \pm 0.2 \mathrm{a}$ & 80 & $0.3 \pm 0.3 \mathrm{a}$ & 20 \\
1 & $0.2 \pm 0.2 \mathrm{a}$ & 20 & $0.2 \pm 0.2 \mathrm{a}$ & 20 & $0.5 \pm 0.3 \mathrm{~b}$ & 40 & $0.3 \pm 0.2 \mathrm{a}$ & 33 \\
10 & $1.2 \pm 0.2 \mathrm{a}$ & 33 & $0.4 \pm 0.3 \mathrm{a}$ & 33 & $0.3 \pm 0.2 \mathrm{~b}$ & 27 & $0.3 \pm 0.3 \mathrm{a}$ & 27 \\
\hline
\end{tabular}

${ }^{*}$ Value represents means \pm SE followed by the different letters show significant differences by Tukey's HSD test $(\mathrm{P} \leq 0.05)$. White fluo. tube $=$ White fluorescent tube

chondroitin sulfate under different sources of lights. Chondroitin sulfate is a polysaccharides type of elicitors, which is widely used as a material for food ingredients, cosmetics and medicine (Toida, 2007). Among the biological polymers, polysaccharides have emerged as promising materials for tissue engineering purposes. This study demonstrated that low concentrations of chondroitin sulfate could promote PLBs, shoots and roots formation of Cymbidium spp. under green and blue LED.

Recently, LEDs have drawn considerable interest as an alternative light source for in vitro propagation. For horticultural researchers and crop producers to benefit from LED use, a variety of preliminary findings should be considered. In Cymbidium orchid cultures, a mixture of red plus blue light alone, enhanced both plant growth and development by increasing the net photosynthesis (Huan and Tanaka, 2004). Kaewjampa et al. (2012) reported that red lighting with interval green lighting enhanced PLBs growth and development more than under red light alone in Cymbidium Waltz 'Idol'. The red spectrum emanating from red fluorescent films increased the proliferation and number of PLBs of $C$. finlaysonianum (Hamada et al., 2009). Another study of Nahar et al. (2015) reported that green light can play an important role in Cymbidium tissue culture comparatively with white fluorescent tube and blue LED. According to this study, reports showed positive effect of chondroitin sulfate under different lights for PLBs multiplication of Cymbidium spp.

\section{Conclusions}

The current study provided experimental data on the effect of different concentrations of chondroitin sulfate of $C$. dayanum and C. finlaysonianum under four sources of lights. Detailed experimental studies were conducted to evaluate the best concentration of PGRs with the best light source for in vitro growth of PLBs, shoots and roots of Cymbidium spp. The mechanism by which chondroitin sulfate elicits plant growth are not yet fully understood, but the principle advantage of this technology is that it may provide continuous, reliable source of PLBs multiplication and could be used for the large-scale in vitro culture propagation.

\section{Acknowledgements}

The authors acknowledge Kochi University, Faculty of Agriculture, Kochi, Japan to conduct this research in the Laboratory of Vegetable and Floricultural Sciences. The authors convey their gratitude to Coach Industries Inc., Japan for providing chondroitin sulfate as sample.

\section{References}

Arditti J, Ernst R (1993). Micropropagation of orchids. Wiley Publishers, New York.

Chugh S, Guha S, Rao IU (2009). Micropropagation of orchids: A review on the potential of different explants. Scientia Horticulturae 122:507-520. 
160

Goto E (2012). Plant production in a closed plant factory with artificial lighting. Acta Horticulturae 956:37-49.

Hamada K, Shimasaki K, Nishimura Y, Egawa H, Yoshida K (2009). Effects of red fluorescent films on the proliferation of Cymbidium finlaysonianum Lindl. PLB cultured in vitro. Horticulture Environment and Biotechnology 50:319-323.

Hathcock JN, Shao A (2007). Risk assessment for glucosamine and chondroitin sulfate. Regulatory Toxicology and Pharmacology 47:78-83.

Hoenecke ME, Bula RJ, Tibbitts TW (1992). Importance of blue photon levels for lettuce seedlings grown under red-light emitting diodes. HortScience 27:427-430.

Huan LVT, Tanaka M (2004). Effects of red and blue light-emitting diodes on callus induction, callus proliferation, and protocormlike body formation from callus in Cymbidium orchid. Environmental Control in Biology 42:57-64.

Johkan M, Shoji K, Goto F, Hashida S, Yoshihara T (2010). Blue light-emitting diode light irradiation of seedlings improves seedling quality and growth after transplanting in red leaf lettuce. HortScience 45:1809-1814.

Kaewjampa N, Shimasaki K (2012). Effects of green LED lighting on organogenesis and superoxide dismutase (SOD) activities in protocorm-like bodies (PLBs) of Cymbidium cultured in vitro. Environmental Control in Biology 50:247-254.

Mitchell CA (2012). Plant lighting in controlled environments for space and earth applications. Acta Horticulturae 956:23-36.

Molini S, Muleo R (2003). Effect of light quality on micropropagation of woody species. In: Jain SM, Ishii K (Eds). Micropropagation of woody trees and fruits. Kluwer Academic Publishers, Dordrecht, The Netherlands pp 3-35.

Morel GM (1960). Producing virus-free cymbidiums. American Orchid Society Bulletin 29:495-497.
Nahar SJ, Shimasaki K, Haque SM (2012). Effect of different light and two polysaccharides on the proliferation of protocromlike bodies of Cymbidium cultured in vitro. Acta Horticulturae 956:307-311.

Nahar SJ, Shimasaki K, Haque SM (2013). Chondroitin sulfate can be a new plant growth regulator for Cymbidium micropropagation. Acta Horticulturae 1014:449-455.

Nahar SJ, Haque SM, Shimasaki K (2015). Organogenesis of Cymbidium finlaysonianum under different sources of lights. American-Eurasian Journal of Agriculture \& Environmental Science 15(10):2095-2101.

Okamoto K, Yanagi T, Kondo S (1997). Growth and morphogenesis of lettuce seedlings raised under different combinations of red and blue light. Acta Horticulturae 435:149-157.

Purnhauser L, Medgysey P, Czako M, Dix JP, Marton L (1987). Stimulation of shoot regeneration in Triticum aestivum and Nicotiana plumbaginifolia Viv tissue cultures using the ethylene inhibitor silver nitrate. Plant Cell Reports 6(1):1-4.

Shimasaki K, Uemoto S (1990). Micropropagation of a terrestrial Cymbidium species using rhizomes developed from seeds and pseudobulbs. Plant Cell Tissue and Organ Culture 22:237-244.

Teixeira da Silva JA, Tanaka M (2006). Embryogenic callus, PLB and TCL paths to regeneration in hybrid Cymbidium (Orchidaceae). Journal of Plant Growth Regulation 25(3):203-210.

Toida T (2007). Biological function of chondroitin sulfate. Foods Food Ingredients Journal of Japan 212:11.

Van L, Huan T, Tanaka M (2004). Effects of red and blue lightemitting diodes on callus induction, callus proliferation, and protocorm-like body formation from callus in Cymbidium orchid. Environmental Control in Biology 42(1):57-64.

Xu ZG, Cui J, Di XR (2009). Effects of different spectral energy distribution on tissue culture of Oncidium in vitro. Journal of Beijing Forestry University 31(4):45-50. 